\title{
Effect of antibiotic growth promoters on intestinal microbiota in food animals: a novel model for studying the relationship between gut microbiota and human obesity?
}

\author{
Jun Lin* \\ Department of Animal Science, The University of Tennessee, Knoxville, TN, USA \\ *Correspondence: jlin6@utk.edu
}

As more children and adults become obese in the U.S. and other countries, obesityassociated diseases are becoming more prevalent worldwide (Poirier et al., 2006). Major chronic diseases linked to obesity include heart disease, stroke, and type 2 diabetes (Kahn et al., 2006; Poirier et al., 2006; Van Gaal et al., 2006). Thus, development of effective preventive and therapeutic strategies against obesity will ultimately reduce the burden of cardiovascular diseases and diabetes. Factors contributing to obesity development are complex. Although it is obvious that human genetics plays an important role in determining body weight, it is widely accepted that the increase in the prevalence of obesity over the past 30 years cannot be attributed to changes in human genome so other factors are responsible for obesity. Recent human and mice studies (Reviewed in DiBaise et al., 2008; Tilg et al., 2009) strongly support a concept that the gut microbiota together with host genotype and lifestyle contribute to the development of obesity. These studies suggest manipulating the microbial populations in the gut may be one means to control body weight. To develop such microbiota-manipulating strategies to aid in weight loss, it is critical to identify potential keystone microorganisms from more than 1,000 different species in the gut. However, there are three major limitations in these pioneering studies which ultimately slow progress in this field. First, previous studies on the relationship between microbiota and obesity (Ley et al., 2005, 2006; Turnbaugh et al., 2006) only analyzed fecal samples which represent the microbiota from the large intestine. However, the small intestine is the principal site for digestion, nutrient assimilation and energy harvest, which is directly relevant to body weight gain. In addition, the microbiota have been observed to vary significantly between small intestine and large intestine (Hayashi et al., 2005; Dumonceaux et al.,
2006). Thus, use of fecal sample from small intestine is critical to reveal the direct relationship between gut microbiota and obesity development. Second, the potential role of microbiota in obesity development has focused on the utilization of indigestible polysaccharides in colon. However, many metabolic functions of microbiota, such as fat digestion, are not captured by only considering polysaccharide utilization. For example, the deconjugation of bile salt complexes by bile salt hydrolases, which are produced by many commensal bacteria (e.g., Lactobacillus), could reduce lipid solubilization and absorption and even lower cholesterol levels in humans (Begley et al., 2006; Ridlon et al., 2006). Lastly, due to technical difficulties, these studies used fecal biota as a surrogate for the entire gut microflora. However, fecal biota may not contain the mucosa-associated microbial populations that are in close contact with the underlying gut epithelium and play a different but important role in nutrient assimilation (Zoetendal et al., 2002; Eckburg et al., 2005). Thus, to identify specific obesity-associated microorganisms, it is essential to develop appropriate animal model and organ systems to overcome the above limitations in studying the relationship between gut microbiota and human obesity.

Although humans are interested in manipulating microbiota to aid in weight loss, the food animal industry has been engaged for decades in manipulating microbiota to increase in weight gain through the use of low-dose antibiotics, usually called antibiotic growth promoters (AGPs) as feed additives (Frost and Woolcock, 1991). At present, the precise mechanisms of growth-promoting effects of AGPs are still unknown. However, it is widely accepted that the growth-promoting effect of AGPs is mediated by the interaction between the AGPs and the intestinal microbiota
(Chapman and Johnson, 2002; Dibner and Richards, 2005) because oral antibiotics do not have growth-promoting effects in germ-free animals (Coates et al., 1955, 1963). Use of AGPs may change the diversity and structure of microbial communities in the animal intestine and ultimately result in an optimal and balanced microbiota for increased energy harvest capacity and better growth performance of food animals. Given that both above agricultural and human biomedical issues rely on the relationship between gut microbiota and body weight gain, we propose examining the effect of AGPs on intestinal microbiota in food animals may provide an innovative model system for us to study the relationship between obesity and gut microbiota and identify obesity-associated microorganisms. Notably, a recent human clinical study showed that a significant weight gain can occur in human after a 6-week treatment of vancomycin plus gentamicin for infective endocarditis with a risk of obesity (Thuny et al., 2010), which further supports our hypothesis to study human obesity using a new model system that builds on more than 50 years of consistent observation of the growth-promoting effect of AGPs on food animal production.

While microbiota in the intestine of food animals have been broadly investigated, very limited information is available concerning the response of intestinal microbiota to AGP treatment (Engberg et al., 2000; Knarreborg et al., 2002; Collier et al., 2003; Smirnov et al., 2005; Dumonceaux et al., 2006; Guban et al., 2006; Wise and Siragusa, 2007). With the aid of culture-independent molecular approaches, the investigations on the effect of AGPs on intestinal microbiota have been initiated in poultry (Knarreborg et al., 2002; Dumonceaux et al., 2006; Wise and Siragusa, 2007) and swine (Collier et al., 2003). As expected, in both swine and poultry the composition of intestinal 
microbiota was influenced by AGP treatment (Knarreborg et al., 2002; Collier et al., 2003; Dumonceaux et al., 2006; Wise and Siragusa, 2007). Particularly, lactobacilli populations were significantly affected by AGPs; AGP treatment could either reduce or increase the abundance of specific lactobacilli species in intestine (Engberg et al., 2000; Knarreborg et al., 2002; Collier et al., 2003; Dumonceaux et al., 2006), which is consistent with the dual effects (beneficial and detrimental) of lactobacilli on the host (Gaskins et al., 2002; Reid et al., 2003; Dibner and Richards, 2005; Heselmans et al., 2005). Although these findings greatly improve our understanding of intestinal microbiota change in response to AGPs, these studies either failed to show the growth-promoting effect of AGPs (Dumonceaux et al., 2006; Wise and Siragusa, 2007) or lacked any growth/nutritional measurements in conjunction with microbial ecology analysis (Knarreborg et al., 2002; Collier et al., 2003), which greatly reduced the relevance of observed microbial structure shift to animal growth. The lack of a growth promotion response of the food animal to AGPs in previous studies is likely due to the use of highly sanitized research facility environments that limits the establishment of diverse microflora in intestine. Thus, to use food animals as a model for studying human obesity, it is critical to simulate industrial conditions for observation of growth promotion in an experimental system, consequently obtaining high quality, growth-relevant intestinal samples for microbial ecology study using complementary genomics and metagenomics approaches.

Similar to the commonly used mice model, food animals also have different normal gut microbiota from human in terms of diversity and relative abundance, which may challenge the identification of obesity-related microorganisms using the proposed food animal model system. However, intestinal microflora in humans, mice as well as food animals are primarily derived from the surrounding environment and diets. So human and food animals share many common gut microflora (Gong et al., 2002; Leser et al., 2002; Lu et al., 2003; Backhed et al., 2005; Eckburg et al., 2005; Zoetendal et al., 2006). Therefore, the findings from the study using the food animal model should provide insights into the relationship between gut microbiota and obesity development in humans. In addition, despite differences in the host genetic makeup, human and animals should share many common themes with respect to the symbiosis relationship between host and gut microbiota for food digestion, nutrient utilization, and energy harvest during evolution. Thus, to better understand host-bacterial mutualism in the intestine, in addition to revealing phylogeny information, it is essential to examine functional and metabolic diversity of gut microbiota affected by AGP usage using recently developed high-throughput approaches, such as metagenomic sequencing of gut microbiota (Turnbaugh et al., 2006) and GeoChip (He et al., 2010).

Among various food animals, chicken appears to be the most appropriate animal model to test our hypothesis for identifying specific obesity-associated microorganisms due to following major reasons. First, compared to the previous human and mice studies (Ley et al., 2005, 2006; Turnbaugh et al., 2006), the ease of handling and the low cost of chickens provide obvious advantages for collecting various samples from different intestinal sites (e.g., jejunum, ileum, mucosa). This enables us to examine microbiota from various intestinal sites and provides stronger statistical power for analyzing complex gut microbiota through greater replication. Second, compared to other food animals (e.g., pig) that have long production cycle and demanding rearing environment, it is much easier to experimentally simulate poultry industrial conditions and thus replicate industrial growth promotion, consequently obtaining growth-relevant intestinal samples for analysis (Waldroup et al., 2005; Hunkapillar et al., 2009). Finally, the chicken has been an important model organism in the research on human genetics, disease, nutrition, immunology, and development (Dodgson, 2003; Stern, 2005; Burt, 2007; Kohonen et al., 2007; Bahr, 2008). The high similarities between the chicken and human genomes with respect to the genes involved in the cell's basic structure and function (Hillier et al., 2004) further supports the generalizability of using chicken as a model organism. Together, examining the effect of AGPs on chicken gut microbiota may offer several significant advantages over mice as an experimental system, and provide a complementary alternative to identify specific obesity-associated microbes in humans.

\section{REFERENCES}

Backhed, F., Ley, R. E., Sonnenburg, J. L., Peterson, D. A. and Gordon, J. I. (2005). Host-bacterial mutualism in the human intestine. Science 307, 1915-1920.

Bahr, J. M. (2008) “The chicken as a model organism," in Sourcebook of Models for Biomedical Research, ed. P.M. Conn (London: Humana Press), 161-167.

Begley, M., Hill, C., and Gahan, C. G. (2006). Bile salt hydrolase activity in probiotics. Appl. Environ. Microbiol. 72, 1729-1738.

Burt, D. W. (2007). Emergence of the chicken as a model organism: implications for agriculture and biology. Poult. Sci. 86, 1460-1471.

Chapman, H. D., and Johnson, Z. B. (2002). Use of antibiotics and roxarsone in broiler chickens in the USA: analysis for the years 1995 to 2000. Poult. Sci. 81, 356-364.

Coates, M. E., Davies, M. K., and Kon, S. K. (1955). The effect of antibiotics on the intestine of the chick. $\mathrm{Br}$. J. Nutr. 9, 110-119.

Coates, M. E., Fuller, R., Harrison, G. F., Lev, M., and Suffolk, S. F. (1963). A comparison of the growth of chicks in the Gustafsson germ-free apparatus and in a conventional environment, with and without dietary supplements of penicillin. Br. J. Nutr. 17, 141-150.

Collier, C. T., Smiricky-Tjardes, M. R., Albin, D. M., Wubben, J. E., Gabert, V. M., Deplancke, B., Bane, D., Anderson, D. B., and Gaskins, H. R. (2003). Molecular ecological analysis of porcine ileal microbiota responses to antimicrobial growth promoters. J. Anim. Sci. 81, 3035-3045.

DiBaise, J. K., Zhang, H., Crowell, M. D., KrajmalnikBrown, R., Decker, G. A., and Rittmann, B. E. (2008). Gut microbiota and its possible relationship with obesity. Mayo Clin. Proc. 83, 460-469.

Dibner, J. J., and Richards, J. D. (2005). Antibiotic growth promoters in agriculture: history and mode of action. Poult. Sci. 84, 634-643.

Dodgson, J. B. (2003). Chicken genome sequence: a centennial gift to poultry genetics. Cytogenet. Genome Res. 102, 291-296.

Dumonceaux, T. J., Hill, J. E., Hemmingsen, S. M., and Van Kessel, A. G. (2006). Characterization of intestinal microbiota and response to dietary virginiamycin supplementation in the broiler chicken. Appl. Environ. Microbiol. 72, 2815-2823.

Eckburg, P. B., Bik, E. M., Bernstein, C. N., Purdom, E., Dethlefsen, L., Sargent, M., Gill, S. R., Nelson, K. E., and Relman, D. A. (2005). Diversity of the human intestinal microbial flora. Science 308, 1635-1638.

Engberg, R. M., Hedemann, M. S., Leser, T. D., and Jensen, B. B. (2000). Effect of zinc bacitracin and salinomycin on intestinal microflora and performance of broilers. Poult. Sci. 79, 1311-1319.

Frost, A. J., and Woolcock, J. B. (1991). "Antibiotics and animal production," in Microbiology of Animals and Animal Products, ed. J. B. Woolcock (New York, NY: Elsevier), 181-194.

Gaskins, H. R., Collier, C. T., and Anderson, D. B. (2002). Antibiotics as growth promotants: mode of action. Anim. Biotechnol. 13, 29-42.

Gong, J., Forster, R. J., Yu, H., Chambers, J. R., Sabour, P. M., Wheatcroft, R., and Chen, S. (2002). Diversity 
and phylogenetic analysis of bacteria in the mucosa of chicken ceca and comparison with bacteria in the cecal lumen. FEMS Microbiol. Lett. 208, 1-7.

Guban, J., Korver, D. R., Allison, G. E., and Tannock, G. W. (2006). Relationship of dietary antimicrobial drug administration with broiler performance, decreased population levels of Lactobacillus salivarius, and reduced bile salt deconjugation in the ileum of broiler chickens Poult. Sci. 85, 2186-2194.

Hayashi, H., Takahashi, R., Nishi, T., Sakamoto, M., and Benno, Y. (2005). Molecular analysis of jejunal, ileal, caecal and recto-sigmoidal human colonic microbiota using $16 \mathrm{~S}$ rRNA gene libraries and terminal restriction fragment length polymorphism. J. Med. Microbiol. 54, 1093-1101.

He, Z., Deng, Y., Van Nostrand, J. D., Tu, Q., Xu, M., Hemme, C. L., Li, X., Wu, L., Gentry, T. J., Yin, Y., Liebich, J., Hazen, T. C., and Zhou, J. (2010). GeoChip 3.0 as a high-throughput tool for analyzing microbial community composition, structure and functional activity. ISME J. 4, 1167-1179.

Heselmans, M., Reid, G., Akkermans, L. M., Savelkoul, H., Timmerman, H., and Rombouts, F. M. (2005). Gut flora in health and disease: potential role of probiotics. Curr. Issues Intest. Microbiol. 6, 1-7.

Hillier, L. W., Miller, W., Birney, E., Warren, W., Hardison, R. C., Ponting, C. P., Bork, P., Burt, D. W., Groenen, M. A. M., Delany, M. E., Dodgson, J. B., Chinwalla, A. T., Cliften, P. F., Clifton, S. W., Delehaunty, K. D., Fronick, C., Fulton, R. S., Graves, T. A., Kremitzki, C., Layman, D., Magrini, V., McPherson, J. D., Miner, T. L., Minx, P., Nash, W. E., Nhan, M. N., Nelson, J. O., Oddy, L. G., Pohl, C. S., Randall-Maher, J., Smith, S. M., Wallis, J. W., Yang, S. P., Romanov, M. N., Rondelli, C. M., Paton, B., Smith, J., Morrice, D., Daniels, L., Tempest, H. G., Robertson, L., Masabanda, J. S., Griffin, D. K., Vignal, A., Fillon, V., Jacobbson, L., Kerje, S., Andersson, L., Crooijmans, R. P. M., Aerts, J., van der Poel, J. J., Ellegren, H., Caldwell, R. B., Hubbard, S. J., Grafham, D. V., Kierzek, A. M., McLaren, S. R., Overton, I. M., Arakawa, H., Beattie, K. J., Bezzubov, Y., Boardman, P. E., Bonfield, J. K., Croning, M. D. R., Davies, R. M., Francis, M. D., Humphray, S. J., Scott, C. E., Taylor, R. G., Tickle, C., Brown, W. R. A., Rogers, J., Buerstedde, J. M., Wilson, S. A., Stubbs, L., Ovcharenko, I., Gordon, L., Lucas, S., Miller, M. M., Inoko, H., Shiina, T., Kaufman, J., Salomonsen, J., Skjoedt, K., Wong, G. K. S., Wang, J., Liu, B., Wang, J., Yu, J., Yang, H. M., Nefedov, M., Koriabine, M., deJong, P. J., Goodstadt, L., Webber, C., Dickens, N. J., Letunic, I., Suyama, M., Torrents, D., von Mering, C., Zdobnov, E. M., Makova, K., Nekrutenko, A., Elnitski, L., Eswara, P., King, D. C., Yang, S., Tyekucheva, S., Radakrishnan, A., Harris, R. S., Chiaromonte, F., Taylor, J., He, J. B., Rijnkels, M., Griffiths-Jones, S., Ureta-Vidal, A., Hoffman, M. M., Severin, J., Searle, S. M. J., Law, A. S., Speed, D., Waddington, D., Cheng, Z., Tuzun, E., Eichler, E., Bao, Z. R., Flicek, P., Shteynberg, D. D., Brent, M. R., Bye, J. M., Huckle, E. J., Chatterji, S.,
Dewey, C., Pachter, L., Kouranov, A., Mourelatos, Z., Hatzigeorgiou, A. G., Paterson, A. H., Ivarie, R., Brandstrom, M., Axelsson, E., Backstrom, N., Berlin, S., Webster, M. T., Pourquie, O., Reymond, A., Ucla, C., Antonarakis, S. E., Long, M. Y., Emerson, J. J., Betran, E., Dupanloup, I., Kaessmann, H., Hinrichs, A. S., Bejerano, G., Furey, T. S., Harte, R. A., Raney, B. Siepel, A., Kent, W. J., Haussler, D., Eyras, E., Castelo, R., Abril, J. F., Castellano, S., Camara, F., Parra, G., Guigo, R., Bourque, G., Tesler, G., Pevzner, P. A., Smit, A., Fulton, L. A., Mardis, E. R., and Wilson, R. K. (2004). Sequence and comparative analysis of the chicken genome provide unique perspectives on vertebrate evolution. Nature 432, 695-716.

Hunkapillar, A., Robbins, K. R., Layton, A., Saxton, A., and Lin, J. (2009). Effect of antibiotic growth promoters on intestinal microbiota in chickens. American Society for Microbiology Annual Branch Meeting, (Knoxville, TN), (Abstract \#12).

Kahn, S. E., Hull, R. L., and Utzschneider, K. M. (2006). Mechanisms linking obesity to insulin resistance and type 2 diabetes. Nature 444, 840-846.

Knarreborg, A., Simon, M. A., Engberg, R. M., Jensen, B. B., and Tannock, G. W. (2002). Effects of dietary fat source and subtherapeutic levels of antibiotic on the bacterial community in the ileum of broiler chickens at various ages. Appl. Environ. Microbiol. 68 5918-5924.

Kohonen, P., Nera, K. P., and Lassila, O. (2007). Avian model for B-cell immunology - new genomes and phylotranscriptomics. Scand. J. Immunol. 66, 113-121.

Leser, T. D., Amenuvor, J. Z., Jensen, T. K., Lindecrona R. H., Boye, M., and Moller, K. (2002). Cultureindependent analysis of gut bacteria: the pig gastrointestinal tract microbiota revisited. Appl. Environ. Microbiol. 68, 673-690.

Ley, R. E., Backhed, F., Turnbaugh, P., Lozupone, C. A. Knight, R. D., and Gordon, J. I. (2005). Obesity alters gut microbial ecology. Proc. Natl. Acad. Sci. U.S.A. 102, 11070-11075

Ley, R. E., Turnbaugh, P. J., Klein, S., and Gordon, J. I. (2006). Microbial ecology: human gut microbes associated with obesity. Nature 444, 1022-1023.

Lu, J., Idris, U., Harmon, B., Hofacre, C., Maurer, J. J., and Lee, M. D. (2003). Diversity and succession of the intestinal bacterial community of the maturing broiler chicken. Appl. Environ. Microbiol. 69, 6816-6824.

Poirier, P., Giles, T. D., Bray, G. A., Hong, Y., Stern, J. S. Pi-Sunyer, F. X., and Eckel, R. H. (2006). Obesity and cardiovascular disease: pathophysiology, evaluation, and effect of weight loss: an update of the 1997 American Heart Association Scientific Statement on Obesity and Heart Disease from the Obesity Committee of the Council on Nutrition, Physical Activity, and Metabolism. Circulation 113, 898-918.

Reid, G., Sanders, M. E., Gaskins, H. R., Gibson, G. R., Mercenier, A., Rastall, R., Roberfroid, M., Rowland, I., Cherbut, C., and Klaenhammer, T. R. (2003). New scientific paradigms for probiotics and prebiotics. $J$. Clin. Gastroenterol. 37, 105-118.

Ridlon, J. M., Kang, D. J., and Hylemon, P. B. (2006). Bile salt biotransformation by human intestinal bacteria. J. Lipid Res. 47, 241-259.

Smirnov, A., Perez, R., Amit-Romach, E., Sklan, D., and Uni, Z. (2005). Mucin dynamics and microbial populations in chicken small intestine are changed by dietary probiotic and antibiotic growth promoter supplementation. J. Nutr. 135, 187-192.

Stern, C. D. (2005). The chick: a great model system becomes even greater. Dev. Cell 8, 9-17.

Thuny, F., Richet, H., Casalta, J. P., Angelakis, E., Habib, G., and Raoult, D. (2010). Vancomycin treatment of infective endocarditis is linked with recently acquired obesity. PLoS ONE 5, e9074. doi: 10.1371/journal. pone. 0009074

Tilg, H., Moschen, A. R., and Kaser, A. (2009). Obesity and the microbiota. Gastroenterology 136, 1476-1483.

Turnbaugh, P. J., Ley, R. E., Mahowald, M. A., Magrini, V., Mardis, E. R., and Gordon, J. I. (2006). An obesityassociated gut microbiome with increased capacity for energy harvest. Nature 444, 1027-1031.

Van Gaal, L. F., Mertens, I. L., and De Block, C. E. (2006). Mechanisms linking obesity with cardiovascular disease. Nature 444, 875-880.

Waldroup, P. W., Yan, F., Keen, C. A., and Zhang, K. Y. (2005). Antibiotics may still have use in broiler production. Feedstuffs 4, 28-33.

Wise, M. G., and Siragusa, G. R. (2007). Quantitative analysis of the intestinal bacterial community in one- to three-week-old commercially reared broiler chickens fed conventional or antibiotic-free vegetable-based diets. J. Appl. Microbiol. 102, 1138-1149.

Zoetendal, E. G., Vaughan, E. E., and de Vos, W. M. (2006). A microbial world within us. Mol. Microbiol. 59, 1639-1650.

Zoetendal, E. G., von Wright, A., Vilpponen-Salmela, T., Ben-Amor, K., Akkermans, A. D., and de Vos W. M. (2002). Mucosa-associated bacteria in the human gastrointestinal tract are uniformly distributed along the colon and differ from the community recovered from feces. Appl. Environ. Microbiol. 68, 3401-3407.

Received: 01 February 2011; accepted: 09 March 2011; published online: 18 March 2011.

Citation: Lin J (2011) Effect of antibiotic growth promoters on intestinal microbiota in food animals: a novel model for studying the relationship between gut microbiota and human obesity? Front. Microbio. 2:53. doi: 10.3389/ fmicb.2011.00053

This article was submitted to Frontiers in Cellular and Infection Microbiology, a specialty of Frontiers in Microbiology.

Copyright $(02011$ Lin. This is an open-access article subject to an exclusive license agreement between the authors and Frontiers Media SA, which permits unrestricted use, distribution, and reproduction in any medium, provided the original authors and source are credited. 